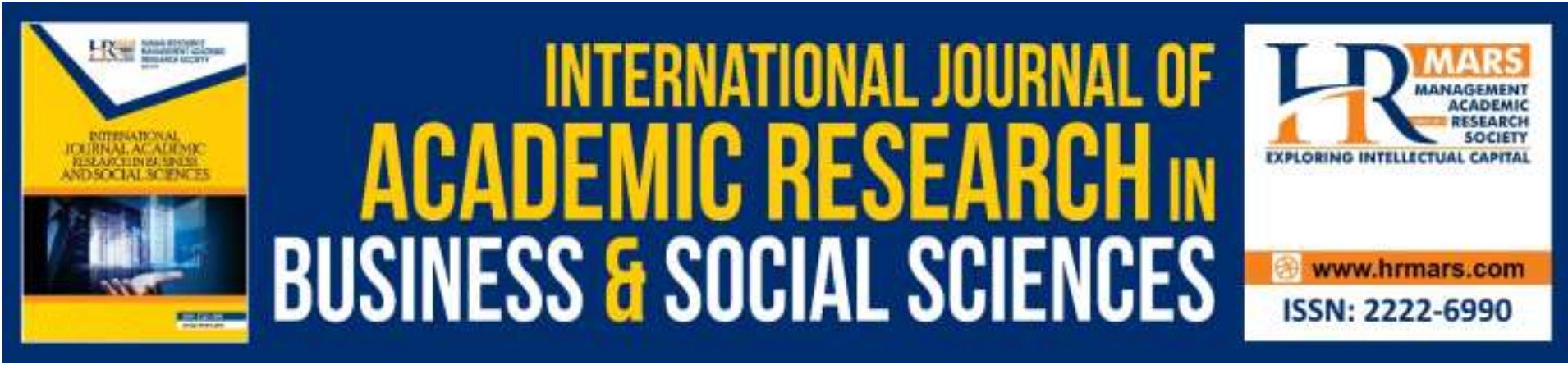

\title{
Appropriateness of Mnemonic Techniques on Mathematics and Social Studies Learning Outcomes in Public Primary School in Machakos Sub-County, Kenya
}

Patricia Mwikali Makau, James Matee Muola, Wycliffe Amukowa

To Link this Article: http://dx.doi.org/10.6007/IJARBSS/v9-i9/6386

DOI: $10.6007 /$ IJARBSS/v9-i9/6386

Received: 17 July 2019, Revised: 14 August 2019, Accepted: 29 August 2019

Published Online: 23 September 2019

In-Text Citation: (Makau, Muola, \& Amukowa, 2019)

To Cite this Article: Makau, P. M., Muola, J. M., \& Amukowa, W. (2019). Appropriateness of Mnemonic

Techniques on Mathematics and Social Studies Learning Outcomes in Public Primary School in Machakos

Sub-County, Kenya. International Journal of Academic Research in Business and Social Sciences, 9(9), 990999.

Copyright: (C) 2019 The Author(s)

Published by Human Resource Management Academic Research Society (www.hrmars.com)

This article is published under the Creative Commons Attribution (CC BY 4.0) license. Anyone may reproduce, distribute, translate and create derivative works of this article (for both commercial and non-commercial purposes), subject to full attribution to the original publication and authors. The full terms of this license may be seen

at: http://creativecommons.org/licences/by/4.0/legalcode

Vol. 9, No. 9, 2019, Pg. 990 - 999

http://hrmars.com/index.php/pages/detail/IJARBSS

JOURNAL HOMEPAGE

Full Terms \& Conditions of access and use can be found at

http://hrmars.com/index.php/pages/detail/publication-ethics 


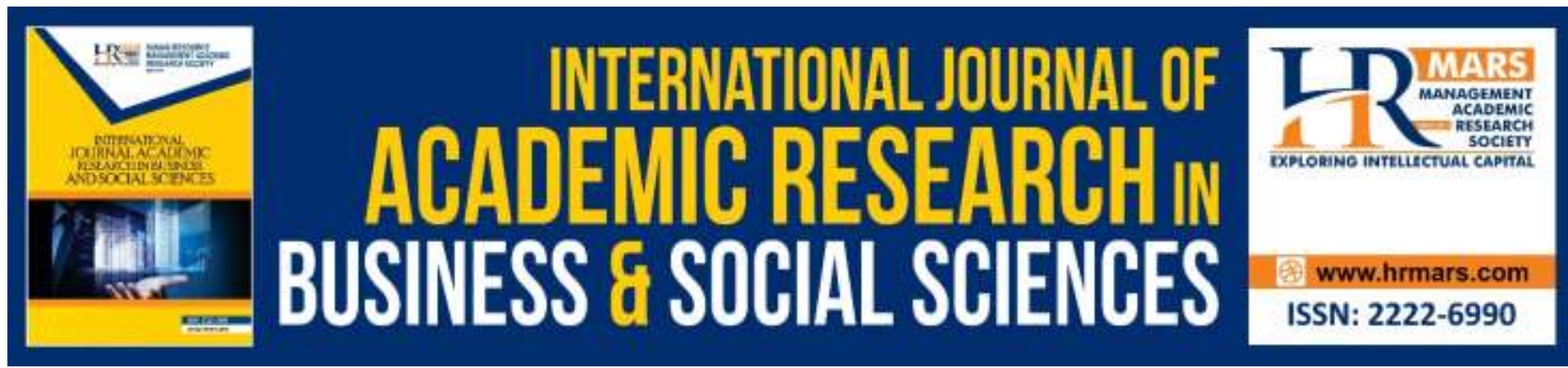

\title{
Appropriateness of Mnemonic Techniques on Mathematics and Social Studies Learning Outcomes in Public Primary School in Machakos Sub-County, Kenya
}

\author{
Patricia Mwikali Makau, Prof. James Matee Muola \\ Department of Educational Psychology, Machakos University \\ Email: patricia.makau@mksu.ac.ke,jmuola@mksu.ac.ke \\ Dr. Wycliffe Amukowa \\ Department of Educational Foundations, Machakos University \\ Email:amukowa@mksu.ac.ke
}

\begin{abstract}
The purpose of this study was to investigate the appropriateness of Mnemonic techniques on mathematics and social studies learning outcomes in primary schools in Machakos subcounty, Kenya. A 4×2 Factorial research design was used to test the appropriateness of three Mnemonic techniques on learning outcomes of mathematics and social studies. Stratified sampling technique was used to categorize schools into three educational zones in Machakos Sub-County. Four schools were then purposefully selected which had similar mean grades in KCPE exams from the three zones. Random sampling was used to assign experimental and control groups. A sample size of 317 class 7 pupils were selected for the study. The following instruments were: Tests which were used to measure learning outcomes of mathematics and social studies. Observation schedule which were as a monitoring tool during Mnemonic techniques intervention process. Questionnaires which were used to measure reported enjoyment and satisfaction among learners during Mnemonic techniques intervention process. Piloting was done in Kathiani Sub-County. Validity and reliability of the research instruments was determined by the split-half correlation method. One-way ANOVA was used to analyse the data. Post-hoc pairwise comparison (LSD) was performed to establish which groups were responsible for the differences. The main findings of the study were: No significant differences $(F(3,147)=0.052, P<0.05)$ were found in mathematics learning outcomes between learners using the three Mnemonic techniques. Hence none of the three Mnemonic techniques was found to be more appropriate for mathematics. In social studies, significant differences $(F(3,146)=4.25, P<0.05)$ were found between learners using the three Mnemonic techniques. Music Mnemonic technique was most appropriate for social studies,
\end{abstract}


pegword, keyword and control group were second, third and fourth respectively. Recommendations of this study was; The findings of this study were based on mathematics and social studies, in order to further contribute to the understanding of the relationship(s) between Mnemonic techniques and learning outcomes a similar study should be replicated in other subjects.

Keywords: Appropriateness, Pegword, Music, Mnemonic Techniques, Learning Outcomes.

\section{Introduction}

The origin of Mnemonics is usually traced to the early Greeks about 500 B.C. Writing of Orator, described the procedure as follows: Persons desiring to train this faculty of memory must select places and form mental images of the things they wish to remember and store these images in those places, so that the order of the places will preserve the order of the things, (Yales, 1966).

Researchers working within the framework of stimulus-response theory in the late 1950s and early 1960 s had often noted that subjects tried to encode the materials presented in a pairedassociate learning task so that a verbal mediator connected the two components in each pair (Clark, Lundsford \& Dallenbach, 1960; Rock, 1957; Underwood \& Schulz, 1960). The prevailing theoretical attitudes at that time indicated that these Mnemonic techniques and the presence of these cognitive encodings should not be major determinants of recall performance compared with such factors as the type of material learned, study time, number of trials, amount and kind of prior learning, and so on. Experimentation in the Ebbinghaus $(1885,1909,2011)$ tradition took pains to ensure that cognitive Mnemonic activities on the part of the learner be minimized. To ensure that rote learning occurred, nonsense syllables were often used as the material to be learned, and this material was often presented at a fast rate. However, it soon became apparent that the Mnemonic strategies used by the subjects were important to learning. Processes such as categorization (Bousfield, 1953), rehearsal (Atkinson and Shiffrin, 1968), the recoding of stimuli (Underwood, 1963), subjective organization (Tulving, 1962), natural language mediation (Montague, Adams and Kiess, 1966), and visual imagery mediation (Paivio, 1971; Ahmed, Majid, \& Zin, 2016), eventually became important areas of investigation in their own right.

Levin and Levin (1993), summarized important factors of using the "threeRs" of Mnemonic use: Recoding, Relating, and Retrieving, with a possible fourth " $R$ " for Rehearsing. Recoding because the information need to be encoded inform which can be easy to for storage. The information to be remembered need to be related to information which is already in the longterm memory. After recoding and relating information, it is the stored and retrieving is made much easier. Similarly, Shimamura (1984); created an acronym Mnemonic to describe elements of Mnemonic learning: "MOVA your memory," with the letters referring to Meaningfulness (e.g., schema-building), Organization (e.g., chunking), Visualization (i.e., imagery), and Attention.

In education, Mnemonics are often used at the initial stage of knowledge acquisition. They may act in this early stage as scaffolding for more permanent schematic knowledge that develops as education advances (Bellezza, 1996). Indeed, psychology courses (especially those taken early in the curriculum, such as Introduction to Psychology) require the mastery of an entirely new area before students can study more complex concepts (Balch, 2005; 
Carney \& Levin, 1998). The types of elaborative strategies incorporated into Mnemonics support this process.

DeLashmuttand Nebraska (2007), did a study on the role of Mnemonics in Learning Mathematics. Their findings suggest that Mnemonics helps many students, but not all of them. Some of the students would rather just learn the math concepts, instead of having to learn a form of Mnemonics to remember the concepts. The research findings reveled that some students in the lower levels used Mnemonics to help retain key math concepts.

Although a great deal of evidence has shown that various Mnemonic techniques can enhance learning outcomes in different subjects. Literature on task appropriateness of Mnemonics techniques on learning outcomes was found to be very scanty. Most research studies published in recent years do not indicate which Mnemonics are most appropriate for different subjects in primary schools. The current study sought to investigate whether learning outcomes of mathematics and social studies can be improved by use of Mnemonic techniques and which among the three Mnemonic techniques (keyword, pegword and music) is most appropriate for mathematics and social studies. This was done by comparing learning outcomes of keyword, pegword and music Mnemonic techniques and control groups in the two subjects.

\section{The Purpose of the Study}

The main aim of this study was to establish task appropriateness of the three Mnemonic techniques on learning outcomes of mathematics and social studies.

\section{Objectives of the Study was}

To investigate the appropriateness of keyword, pegword and Music Mnemonic techniques on learning outcomes of social studies and mathematics in Public upper primary pupils

\section{The Null Hypothesis of the Study was}

HO There is no significant difference in learning outcomes of mathematic and social studies subjects between learners using keyword, pegword and Music Mnemonic Techniques Public upper primary pupils

\section{Research Methodology Research Design}

Research Design is arrangement of conditions for collection and analysis of data in a manner that aims to combine relevance to the research purpose with economy in procedure, (Kothari, 2004). The study adopted Quasi -experimental research design to collect data. This research design is useful when investigating cause-effect relationships between independent and dependent variables in situations which do not permit randomization.

Under Quasi- experimental research design, 4×2 factorial-experimental design was adopted. Factorial-experimental involved having three independent variables (Pegword, Keyword and Music Mnemonic techniques) and control group which were examined at immediate and delayed recall Learning outcomes. The dependent variable was learning outcomes. A sample 317 pupils were used for the study. 


\section{Research Instruments}

The researcher used the four research instruments: Observation schedule, questioners and Achievement tests.

\section{Data Collection}

Data collection refers to gathering specific information aimed at providing or refuting some facts (Kombo, 2006.

Two stages were adopted for data collection procedure. These stages involved

$>$ Intervention stage

$>$ Measuring stage

\section{Stage 1: Intervention}

The researcher started by first training subject teachers and research assistants on how to use the three Mnemonic techniques instruction method in teaching.

The teachers then used Mnemonic instruction methods for the three treatment groups and conventional method of instruction for control group.

\section{Stage Two: Measurement of learning outcomes}

Post-test were administered to all the groups which were involved in the study. The tests were then scored and analyzed.

\section{Findings}

Appropriateness of Keyword, Pegword and Music Mnemonic Techniques on Mathematics and Social Studies

The researcher sought to establish whether there were significant differences between learners exposed to learning through keyword, pegword and music Mnemonic instruction methods and mathematics and social studies learning outcomes. Data was obtained from post- test scores which were administered after intervention process of the three Mnemonic technique instruction methods and a control group. The data was then analyzed and presented descriptively and inferentially.

\section{Descriptive Analysis for Mnemonic techniques scores mathematics and social studies learning outcomes}

In order to establish the differences in mathematics and social studies learning outcomes between learners using keyword, pegword and Music Mnemonic instruction methods the raw data was first analysed descriptively. Table 1 presents the findings. 
Table 1: Descriptive analysis for Mathematics and Social Studies

\begin{tabular}{lllllll}
\hline Subject & Mnemonic Device & $\mathrm{N}$ & Minimum & Maximum & Mean & $\begin{array}{l}\text { Std. } \\
\text { Deviation }\end{array}$ \\
\hline Maths & Pegword & 44 & 26.00 & 68.00 & 49.90 & 9.526 \\
& Keyword & 35 & 23.00 & 86.00 & 50.54 & 16.41 \\
& Music & 35 & 34.00 & 80.00 & 50.69 & 12.01 \\
& Control Group & 37 & 26.00 & 72.00 & 50.89 & 13.33 \\
Social & Pegword & 44 & 17.00 & 92.00 & 49.14 & 16.74 \\
Studies & Keyword & 35 & 21.00 & 78.00 & 44.80 & 12.52 \\
& Music & 34 & 17.00 & 73.00 & 52.88 & 13.05 \\
& Control Group & 37 & 18.00 & 54.00 & 42.65 & 8.32 \\
\hline
\end{tabular}

Table 1 show that Social studies had much higher mean differences between the three Mnemonic instruction methods and control group compared to Mathematics which had small mean differences between the three Mnemonic instruction methods and control group. In mathematics the mean differences were not significant with control group having the highest mean 50.89 and standard deviation 13.33, music followed second with mean score 50.69 and standard deviation of 12.01, keyword was third with a mean score 50.54 and standard deviation 16.41, finally, pegword had the lowest of mean score 49.54 and standard deviation 9.53. This is an indication that Mnemonic technique instruction methods did not have any advantage over control group on learning outcomes of mathematics. On the other hand, Social studies had higher mean score differences among the three Mnemonic instruction methods and control group. Music had the highest mean score of 52.88 and standard deviation of 13.05, pegword was second with a mean score of 49.14 and standard deviation of 16.74, keyword was third with a mean score of 44.80 and standard deviation of 8.32 and lastly control group had the lowest mean score of 42.65 and standard deviation of 9.53.

\section{Inferential Analysis for differences in Mnemonic techniques instruction method on Mathematics and Social studies learning outcomes.}

To test the null hypothesis $\left(\mathrm{H}_{0}\right)$ : Which stated that there is no significant differences in mathematics and social studies learning outcomes between learners using keyword, pegword and music Mnemonic instruction methods. One-way ANOVA was done. This hypothesis was divided into two supplementary hypotheses to test for the following;

i. Significant differences between learners exposed to learning through different Mnemonic technique and mathematics learning outcomes and

ii. Significant differences between learners exposed to learning through Mnemonic techniques and social studies learning outcomes. 
Table 2 One-way ANOVA analysis for Mnemonic Technique on Mathematics and Social Studies Learning Outcomes

\begin{tabular}{|c|c|c|c|c|c|c|}
\hline Subject & & $\begin{array}{l}\text { Sum of } \\
\text { Squares }\end{array}$ & $d f$ & $\begin{array}{l}\text { Mean } \\
\text { Square }\end{array}$ & $F$ & Sig. \\
\hline \multirow[t]{3}{*}{ Maths } & $\begin{array}{l}\text { Between } \\
\text { Groups }\end{array}$ & 25.79 & 3 & 8.60 & .05 & .984 \\
\hline & Within Groups & 24357.683 & 147 & 165.70 & & \\
\hline & Total & 24383.47 & 150 & & & \\
\hline \multirow[t]{3}{*}{$\begin{array}{l}\text { Social } \\
\text { Studies }\end{array}$} & $\begin{array}{l}\text { Between } \\
\text { Groups }\end{array}$ & 2226.35 & 3 & 742.12 & 4.25 & .007 \\
\hline & Within Groups & 25502.74 & 146 & 174.68 & & \\
\hline & Total & 27729.09 & 149 & & & \\
\hline
\end{tabular}

\section{Supplementary Hypotheses}

$\mathrm{HO}_{\mathrm{a}}$ : There is no Significant Difference in Learning Outcomes of Mathematics between Learners using Keyword, Pegword and Music Mnemonic Techniques

Decision: The null hypothesis was retained. No significant differences $(F(3,147)=0.052, P<$ 0.05) were found in mathematics learning outcomes between learners using various Mnemonic instruction methods.

The implication of this finding is that learners did not benefit from the Mnemonic instruction methods. Surprisingly the control group had the highest mean although they were not significance. The results indicated that learners were better of using conventional methods of teaching other than Mnemonic techniques to learn and retain mathematics concepts.

The findings are consistent with studies done by DeLashmutt and Nebraska (2007), their findings suggested that Mnemonics helps some students to learn mathematics but not all of them. Some of the students would rather just learn the mathematics concepts, instead of having to learn a form of Mnemonics to remember the concepts. In the current study the investigator used class 7 upper primary pupils, learners may have preferred using conventional methods rather having to learn a form of Mnemonics technique first. Inadequate time to practice and internalize mnemonic techniques may have affected the use of mnemonic techniques.

These findings contradicted the findings of an earlier study done by Irish (2002), whose in his findings revealed that there was significant difference in performance of basic multiplication facts with respect to the length of treatment.

$\mathrm{HO}_{\mathrm{b}}$ : There is no Significant Difference in Learning Outcomes of Social Studies between Learners Using Keyword, Pegword and Music Mnemonic Techniques

The data in Table 2 show that indeed there was significant mean differences $F(3,146)=4.25$, $\mathrm{P}<0.05$ ) in learning outcomes social studies between learners using pegword, keyword, music Mnemonic techniques and control groups. 
Table 3: Pairwise comparisons analysis for Mnemonic Technique in Relation to Social Studies Learning Outcomes.

\begin{tabular}{|c|c|c|c|c|c|c|c|}
\hline \multirow[t]{2}{*}{ Subject } & \multirow{2}{*}{$\begin{array}{l}\text { (I) } \\
\text { Mnemonic } \\
\text { Device }\end{array}$} & \multirow[t]{2}{*}{$\begin{array}{l}\text { (J) Mnemonic } \\
\text { Device }\end{array}$} & \multirow{2}{*}{$\begin{array}{c}\text { Mean } \\
\text { Differen } \\
\text { ce }(I-J)\end{array}$} & \multirow[t]{2}{*}{$\begin{array}{l}\text { Std. } \\
\text { Error }\end{array}$} & \multirow[t]{2}{*}{ Sig. } & \multicolumn{2}{|c|}{$\begin{array}{c}\text { 95\% Confidence } \\
\text { Interval }\end{array}$} \\
\hline & & & & & & $\begin{array}{l}\text { Lower } \\
\text { Bound }\end{array}$ & $\begin{array}{l}\text { Upper } \\
\text { Bound }\end{array}$ \\
\hline \multirow{12}{*}{$\begin{array}{l}\text { Social } \\
\text { studies }\end{array}$} & \multirow{4}{*}{ Pegword } & Keyword & 4.34 & 2.99 & .15 & -1.58 & 10.25 \\
\hline & & Music & -3.75 & 3.02 & .22 & -9.72 & 2.22 \\
\hline & & Control Group & $6.49^{*}$ & 2.95 & .03 & .66 & 12.31 \\
\hline & & pegword & -4.34 & 2.99 & .15 & -10.25 & 1.58 \\
\hline & \multirow[t]{3}{*}{ Keyword } & Music & $-8.08^{*}$ & 3.18 & .01 & -14.38 & -1.80 \\
\hline & & Control Group & 2.15 & 3.12 & .49 & -4.01 & 8.31 \\
\hline & & pegword & 3.75 & 3.02 & .22 & -2.22 & 9.71 \\
\hline & \multirow[t]{2}{*}{ Music } & Keyword & $8.08^{*}$ & 3.19 & .01 & 1.80 & 14.37 \\
\hline & & Control Group & $10.23^{*}$ & 3.14 & .00 & 4.03 & 16.44 \\
\hline & \multirow{3}{*}{$\begin{array}{l}\text { Control } \\
\text { Group }\end{array}$} & Pegword & $-6.45^{*}$ & 2.95 & .03 & -12.31 & -.66 \\
\hline & & Keyword & -2.15 & 3.12 & .49 & -8.31 & 4.01 \\
\hline & & Music & $-10.23^{*}$ & 3.14 & .00 & -16.44 & -4.03 \\
\hline
\end{tabular}

*. The mean difference was significant at the 0.05 level.

Post-hoc results showed significant different in Social studies learning outcomes scores among subjects exposed to learning through Music, kegword and control group. Further, participants exposed to Music had significantly higher mean as compared to the mean scores obtained using pegword and the control group. The mean scores of subjects exposed to peyword mnemonic technique were not significant difference. Music was found to be most appropriate Mnemonic technique to learn and retain social studies content among learners, pegword was second and keyword was least appropriate among the three mnemonic instruction methods.

This findings agrees with the study done earlier by Mastropieri and Scruggs (1998). In their study to determine effectiveness of Mnemonic instruction in social studies. Their findings revealed that under Mnemonic instruction treatment conditions students outperformed control group on both immediate and delayed learning outcoms. (Ahmed, Khalid, Ammar, \& Shah, 2017).

\section{Conclusions}

Appropriateness of Keyword, Pegword and Music Mnemonic Techniques on Mathematics and Social Studies learning Outcomes

The findings resulted in two conclusions as follows. First, no significant differences were found in learning outcomes of mathematics between learners taught using keyword, pegword and music Mnemonic techniques. Hence mnemonic techniques had no effect on mathematics learning outcomes. It is the researcher's suggestion that, Mnemonic techniques help some learners to learn mathematics but not all of them and that some of the learners would rather just learn the math concepts, instead of having to learn a form of Mnemonics to remember the concepts. 
Second, there were significant differences in social studies learning outcomes between learners exposed to learning through different mnemonic techniques. Post-hoc pairwise comparison indicated that mean differences were significant in Social studies learning outcomes scores among subjects exposed to Music, keyword and control group., Music was most appropriate mnemonic technique in improving social studies learning outcomes while keyword was least appropriate. It is researcher's suggestion that, music m should be used to learn social studies subject.

\section{Recommendations}

The findings of this study were based on mathematics and social studies similar study should be replicated in other subjects.

The findings of this study have shown that keyword, pegword and music Mnemonic techniques have a positive and significant predictive value on social studies learning outcomes. However, the study did not investigate the relationship between social studies and other Mnemonic techniques. For this purpose, there is need to carry out further research to identify the effect of other Mnemonic techniques on social studies.

The findings of this study were based on primary school pupils. Similar studies should be replicated with samples from upper levels such as secondary schools and universities.

\section{References}

Ahmed, U., Khalid, N., Ammar, A., \& Shah, M. H. (2017). Assessing moderation of employee engagement on the relationship between work discretion, job clarity and business performance in the banking sector of Pakistan. Asian Economic and Financial Review, 7(12), 1197-121. https://doi.org/10.18488/journal.aefr.2017.712.1197.1210

Ahmed, U., Majid, A. H. A., \& Zin, M. M. (2016). Moderation of meaningful work on the relationship of supervisor support and coworker support with work engagement. The Journal of Business, Economics, and Environmental Studies (JBEES), 6(3), 15-20.

Balch, W. R. (2005). Elaborations of introductory psychology terms: Effects on test performance and subjective ratings. Teaching of Psychology, 32, 2934. http://dx.doi.org/10.1207/s15328023top3201-7

Bellezza, F. (1996). Mnemonic methods to enhance storage and retrieval. In E. L. Bjork, \& RA. Bjork (Eds.), Memory: Handbook of perception and cognition (pp. 345-380). San Diego, CA: Academic Press.

DeLashmutt, K. (2007). A study of the role of Mnemonics in Learning Mathematics. Summative projects for MA Degree. 19.

Irish, C. (2002). Mnemonics Using Peg- and Keyword Mnemonics and Computer-Assisted Instruction to Enhance Basic Multiplication Performance in Elementary Students with Learning and Cognitive Disabilitie,: British Journal of Sports Medicine

Kothari, C. R. (2011). Research methodology and techniques ( $2^{\text {nd }}$ ed.) Delhi: New Age International Limited Publishers.

Kombo, D. K. \& Tromp, L. A. (2011). Proposal and theses writing: Nairobi: Pauline Publication 
Levin, J. R. (1993). Mnemonic strategies and classroom learning: A twenty-year report card.Elementary School Journal, 94(2), 235-244.

Levin, J. R., Shriberg L. K., \& Berry J. K, (1983). A Concrete Strategy for Remembering Abstract Prose: American Educational Research journal.

Levin (Eds.), Cognitive strategy research: Psychological foundations (pp. 5) New York: Springer-Verlag.

Levin, Dretzke, B. J, McCormick, C. B., Scruggs, T. E., McGivern, J. E., \& Mastropieri, M. A. (1983), Learning via Mnemonic Pictures: Analysis of the Presidential Process Educational Communication and Technology Journal, Vol. 31, No. 3, pp. 161-173

Levin, J. R., Shriberg, L. K., Miller, G. E., \& McCormick, C. B. (1982). The keyword method in the classroom: How to remember the states and their capitals. Elementary School Journal, 1980, 80, 186-191.

Machakos County Government, (2017). Retrieved January 2019 from http://www.machakosgovernment.com.

Miller, G. A, Galanter E., \& Pribram, K. H. (1960). Plans and the structure of behavior. New York: Henry Holt.

Paivio, A. (1971), Imagery in recall and recognition. In J. Brown (Ed.), Recall and recognition. London: 